\title{
Influence of Swimming Speed on Metabolic Rates of Juvenile Pacific Bluefin Tuna and Yellowfin Tuna
}

\author{
Jason M. Blank ${ }^{1, *}$ \\ Charles J. Farwell ${ }^{2}$ \\ Jeffery M. Morrissette ${ }^{1}$ \\ Robert J. Schallert ${ }^{2}$ \\ Barbara A. Block ${ }^{1}$ \\ ${ }^{1}$ Tuna Research and Conservation Center, Hopkins Marine \\ Station, Stanford University, Oceanview Boulevard, Pacific \\ Grove, California 93950; ${ }^{2}$ Monterey Bay Aquarium, Cannery \\ Row, Monterey, California 93940
}

Accepted 9/19/2006; Electronically Published 1/5/2007

\section{ABSTRACT}

Bluefin tuna are endothermic and have higher temperatures, heart rates, and cardiac outputs than tropical tuna. We hypothesized that the increased cardiovascular capacity to deliver oxygen in bluefin may be associated with the evolution of higher metabolic rates. This study measured the oxygen consumption of juvenile Pacific bluefin Thunnus orientalis and yellowfin tuna Thunnus albacares swimming in a swim-tunnel respirometer at $20^{\circ} \mathrm{C}$. Oxygen consumption $\left(\dot{\mathrm{Mo}}_{2}\right)$ of bluefin $(7.1-9.4 \mathrm{~kg})$ ranged from $235 \pm 38 \mathrm{mg} \mathrm{kg}^{-1} \mathrm{~h}^{-1}$ at 0.85 body length (BL) $\mathrm{s}^{-1}$ to $498 \pm 55 \mathrm{mg} \mathrm{kg}^{-1} \mathrm{~h}^{-1}$ at $1.80 \mathrm{BL} \mathrm{s}^{-1}$. Minimal metabolic rates of swimming bluefin were $222 \pm 24 \mathrm{mg} \mathrm{O}_{2} \mathrm{~kg}^{-1} \mathrm{~h}^{-1}$ at speeds of 0.75 to $1.0 \mathrm{BL} \mathrm{s}^{-1} \cdot \dot{\mathrm{Mo}}_{2}$ of $T$. albacares $(3.7-7.4 \mathrm{~kg}$ ) ranged from $164 \pm 18 \mathrm{mg} \mathrm{kg}^{-1} \mathrm{~h}^{-1}$ at $0.65 \mathrm{BL} \mathrm{s}^{-1}$ to $405 \pm$ $105 \mathrm{mg} \mathrm{kg}^{-1} \mathrm{~h}^{-1}$ at $1.8 \mathrm{BL} \mathrm{s}^{-1}$. Bluefin tuna had higher metabolic rates than yellowfin tuna at all swimming speeds tested. At a given speed, bluefin had higher metabolic rates and swam with higher tailbeat frequencies and shorter stride lengths than yellowfin. The higher $\dot{\mathrm{Mo}}_{2}$ recorded in Pacific bluefin tuna is consistent with the elevated cardiac performance and enhanced capacity for excitation-contraction coupling in cardiac myocytes of these fish. These physiological traits may underlie thermal-niche expansion of bluefin tuna relative to tropical tuna species.

\footnotetext{
*Corresponding author; e-mail: jblank@uci.edu.
}

Physiological and Biochemical Zoology 80(2):167-177. 2007. (C) 2007 by The University of Chicago. All rights reserved. 1522-2152/2007/8002-6202\$15.00

\section{Introduction}

Tunas have a remarkable suite of morphological and physiological traits that enhance performance, including thunniform swimming mechanics, high cardiac outputs, and high metabolic rates (Fierstine and Walters 1968; Carey and Lawson 1973; Korsmeyer and Dewar 2001). All tunas have countercurrent vascular heat exchangers (retia mirabilia) that conserve metabolic heat, allowing metabolically active tissues to be warmed above ambient water temperatures. Among tunas, the bluefin species (Thunnus thynnus, Thunnus orientalis, and Thunnus maccoyii) are distinct in important aspects of their physiology and ecology, including higher internal temperatures, enhanced cardiac performance, and extension of their habitat into subpolar seas (Carey and Teal 1969; Blank et al. 2004; Block et al. 2005). These traits suggest that bluefin tuna may have higher metabolic rates than tropical species; however, bluefin have only recently been available for laboratory-based physiological measurement.

Measurements of both standard and active metabolic rates in yellowfin tuna, kawakawa, skipjack, and albacore have indicated that tuna metabolic rates are elevated relative to other teleosts (Korsmeyer and Dewar 2001). Such measurements are technically difficult and are complicated by the need for tunas to swim continuously in order to ventilate their gills and to maintain hydrodynamic equilibrium (Magnuson 1973). As a result, standard metabolic rates (SMRs) of scombrids have been estimated using a variety of techniques, including oxygen consumption of fish immobilized with spinal anesthesia (Brill 1979, 1987), $\mathrm{O}_{2}$ consumption of fish swimming freely (Gooding et al. 1981; Boggs and Kitchell 1991; Freund 1999) or at controlled speeds in swim tunnels (Graham and Laurs 1982; Graham et al. 1989; Dewar and Graham 1994a; Sepulveda and Dickson 2000; Dickson et al. 2002), and loss of body mass during starvation (Boggs and Kitchell 1991). Collectively, these studies indicate that yellowfin tuna, skipjack, kawakawa, and albacore have high SMRs of 200 to $500 \mathrm{mg} \mathrm{O}_{2} \mathrm{~kg}^{-1} \mathrm{~h}^{-1}$ at $25^{\circ} \mathrm{C}$. However, most of these studies have involved measurements within the first $12 \mathrm{~h}$ in the experimental apparatus, when the fish may have been recovering from handling stress, thus potentially elevating measurements of metabolic rates.

Measurements of maximal metabolic rate $\left(\dot{\mathrm{Mo}}_{2 \max }\right)$ in tunas are especially limited due to the difficulty of designing a flume that can accommodate the large body size and high swimming speeds of burst activity. Metabolic rates of 2,200 to 2,500 mg $\mathrm{O}_{2} \mathrm{~kg}^{-1} \mathrm{~h}^{-1}$ have been recorded in 2-kg skipjack tuna shortly 
after capture at sea or introduction to a swim tunnel (Gooding et al. 1981; Dewar and Graham 1994a), and metabolic rates up to $1,290 \mathrm{mg} \mathrm{kg}^{-1} \mathrm{~h}^{-1}$ have been recorded in a single $2-\mathrm{kg}$ yellowfin tuna exercising in a swim tunnel (Dewar and Graham 1994a). It is unclear whether these values represent $\dot{M o}_{2 \max }$ of tuna or an intermediate elevation of metabolism during recovery from exercise stress.

Despite these difficulties, measurements to date indicate that juvenile yellowfin, skipjack, and albacore tunas have elevated routine and SMRs compared with other fish. The high metabolic rates of tunas are supported by a suite of morphological and physiological adaptations for oxygen uptake and transport, including large gill surface areas and thin gill epithelia (Muir and Hughes 1969; Hughes 1984); large hearts, high proportions of compact myocardium, and well-developed coronary circulations (Poupa et al. 1981; Farrell et al. 1992); and high heart rates, cardiac outputs, and ventricular pressures (Brill and Bushnell 2001; Blank et al. 2004). Oxygen uptake is enhanced by high levels of myoglobin in cardiac and skeletal muscle (Giovane et al. 1980; Poupa et al. 1981; Dickson 1996; Marcinek 2000) and high levels of aerobic enzymes in muscle and other tissues (Modigh and Tota 1975; Guppy et al. 1979; Moyes et al. 1992; Dickson 1996; Freund 1999).

To date, most measurements of metabolic rate in tunas have been conducted in tropical species, including yellowfin (Thunnus albacares), skipjack (T. alalunga) and kawakawa (Euthynnus affinis). While the habitats of Pacific bluefin tuna and yellowfin tuna overlap for a portion of their range, all bluefin tunas extend their geographic niches into higher latitudes, cooler temperate and (in southern and Atlantic bluefin) subpolar waters. Atlantic bluefin experience sea-surface temperatures as low as $2^{\circ} \mathrm{C}$ (Block et al. 2001; Kitagawa et al. 2002; Block et al. 2005), and small juvenile Pacific bluefin range into surface waters of $11^{\circ} \mathrm{C}$ or less off northern California. Yellowfin tuna primarily inhabit waters of $17^{\circ} \mathrm{C}$ and above, although they encounter cooler waters for short durations during foraging dives (Block et al. 1997).

The bluefin tuna lineages have more extensive lateral countercurrent retia mirabilia than tropical tunas and retain heat in the viscera as well as the slow-twitch muscle, brain, and eyes (Kishinouye 1923; Linthicum and Carey 1972; Carey and Lawson 1973). Atlantic bluefin tuna of large body size (200-400 $\mathrm{kg}$ ) can maintain muscle and visceral temperatures up to $21^{\circ} \mathrm{C}$ above ambient water temperature for prolonged periods (months), increasing the rates of physiological processes such as muscle contraction and digestion (Carey and Teal 1969; Stevens and McLeese 1984; Block et al. 2001). Electronic tagging studies indicate that small Pacific bluefin $(8-10 \mathrm{~kg})$ similar in size to those in this study are capable of maintaining visceral temperatures up to $12^{\circ} \mathrm{C}$ above ambient water temperature (Kitagawa et al. 2006) following daily feeding events. Muscle temperatures $8^{\circ} \mathrm{C}$ above ambient have been recorded in 10-20- $\mathrm{kg}$ Pacific bluefin swimming in mixed layer waters of $17^{\circ}-21^{\circ} \mathrm{C}$ (Marcinek et al. 2001).

Laboratory measurements have shown that Pacific bluefin have higher heart rates and cardiac outputs than yellowfin tuna at temperatures of $2^{\circ}-20^{\circ} \mathrm{C}$ and maintain cardiac performance at lower temperatures than yellowfin (Blank et al. 2002, 2004). These differences are correlated with higher levels of sarcoplasmic reticulum $\mathrm{Ca}^{2+}$ ATPase (SERCA 2) in bluefin heart cells compared with those of yellowfin tuna (LandeiraFernandez et al. 2004). L-type $\mathrm{Ca}^{2+}$ channel densities and $\mathrm{Ca}^{2+}$ current kinetics are enhanced in bluefin tuna cardiac myocytes (Shiels et al. 2004) relative to ectothermic scombrids. Enhanced cardiac performance at the organ and cellular level in bluefin tuna combined with elevated tissue temperatures suggests the possibility of high rates of whole-animal oxygen consumption. To test the hypothesis that bluefin have higher metabolic rates than tropical yellowfin tuna, we measured the rate of oxygen consumption of Pacific bluefin and yellowfin tuna as the animals swam in a swim-tunnel respirometer. Oxygen consumption $\left(\dot{\mathrm{Mo}}_{2}\right)$ was measured across a range of swimming speeds in order to determine the minimum metabolic rate during swimming for each species.

\section{Material and Methods}

\section{Experimental Animals}

Pacific bluefin tuna (Thunnus orientalis, $N=6$ ) and yellowfin tuna (Thunnus albacares, $N=5$ ) were captured on barbless circle hooks off San Diego, California, at latitudes of $31^{\circ} 20^{\prime}$ to $31^{\circ} 30^{\prime} \mathrm{N}$ and longitudes of $117^{\circ} 24^{\prime}$ to $117^{\circ} 30^{\prime} \mathrm{W}$ in waters of $20^{\circ}$ to $20.1^{\circ} \mathrm{C}$ sea-surface temperature. Following capture, the tuna were held on board the fishing vessel in wells filled with aerated seawater for 1 to $2 \mathrm{~d}$ and transported by truck to the Tuna Research and Conservation Center (TRCC) in Pacific Grove, California. At the TRCC, bluefin and yellowfin tunas were held together in $109-\mathrm{m}^{3}$ circular tanks containing seawater at $20^{\circ} \pm 1.0^{\circ} \mathrm{C}$, a temperature that is conducive to maintaining both species in captivity. The tunas were fed a diet of squid, sardines, and enriched gelatin three times per week, as previously described (Farwell 2001). Tunas were used for experiments between 13 and $176 \mathrm{~d}$ after capture. Mean body size of bluefin used in the swim tunnel was $74 \pm 3 \mathrm{~cm}$ (range 70-78 $\mathrm{cm}$ ) and $8.3 \pm 0.8 \mathrm{~kg}$ (range 7.1-9.4 kg). Mean body size of yellowfin was $67 \pm 7 \mathrm{~cm}$ (range 60-76 cm) and $5.4 \pm 1.6 \mathrm{~kg}$ (range 3.7-7.4 kg). All fish fed well in captivity before the experiments, but food was withheld from the entire tank for 45 to $72 \mathrm{~h}$ before capture of a fish for introduction to the swim tunnel. All procedures were approved by the Stanford University Animal Care and Use Committee (protocol 7297). 
Swim-Tunnel Design

The swim tunnel consisted of an 870-L acrylic respirometer chamber contained in a 1,500-L external tank for thermal insulation (Loligo Systems, Tjele, Denmark). The working section in which the fish was held measured $45 \mathrm{~cm} \times 45 \mathrm{~cm} \times 135$ $\mathrm{cm}$ and was square in cross section. The return loop was of equal cross section and separated horizontally from the working section. Flow was generated by a propeller driven by a $6-\mathrm{kW}$ motor. Turbulence was minimized by the presence of radial vanes downstream of the propeller, vertical vanes in curved sections, and two honeycomb sections placed upstream of the working section. The sides of the working section were marked with vertical stripes of black tape at $10-\mathrm{cm}$ intervals to assist the fish in maintaining position in the tank.

Water velocities were calibrated by video analysis of dye injections and corrected for solid blocking effects for each fish according to Bell and Terhune (1970). Fish cross-sectional area ranged from $6 \%$ to $10 \%$ of working section area, and blocking correction ranged from $5 \%$ to $11 \%$ of uncorrected velocity. Seawater that was continuously filtered and aerated was supplied to the respirometer from a 20,000-L reservoir. The temperature of the swim tunnel was maintained at $20^{\circ} \pm 0.1^{\circ} \mathrm{C}$, matching the acclimation temperature, by the addition of warm or cold filtered seawater to the reservoir and use of a $6,800-\mathrm{W}$ heat pump. The entire swim tunnel was enclosed by black plastic sheeting to minimize light fluctuations, and access to the building was limited while the experiment was in progress to minimize disturbance of the fish. A mirror was mounted at a $45^{\circ}$ angle above the working section of the swim tunnel, and a video camera was inserted through the side of the enclosure to provide an overhead view of the swimming fish.

\section{Introduction of the Fish}

Tunas were captured by lowering the water level in the holding tank and gently guiding an individual fish into a water-filled nylon sling (Farwell 2001). The curved-fork length of the fish was measured, and the sling filled with the fish and seawater was carried to the swim tunnel and submerged in the working section, where the fish was released into the oncoming flow stream. One person remained with the fish and kept it from brushing the sides and back of the working section until the fish became accustomed to the swim tunnel and began swimming steadily. During this time, the swim tunnel was flushed continuously with seawater from the external reservoir. Initial speeds of 1.0 to 1.15 body lengths (BL) $\mathrm{s}^{-1}$ facilitated acclimation of bluefin tuna to the swim tunnel, while yellowfin appeared to prefer lower speeds of 0.9 to $1.0 \mathrm{BL} \mathrm{s}^{-1}$. Once the fish was swimming steadily, approximately 30 to $45 \mathrm{~min}$ after introduction, the lid of the working section was secured, and oxygen consumption measurements were initiated. Fish that did not swim steadily were returned to the holding tank.
Respirometry Procedures

Oxygen consumption $\left(\dot{\mathrm{Mo}}_{2}\right)$ was measured by intermittent respirometry as described by Steffensen (1989). The swim tunnel was closed for $10 \mathrm{~min}$ for measurements of oxygen consumption and then flushed with aerated seawater from the external tank for $10 \mathrm{~min}$ to restore dissolved oxygen levels. These steps were repeated throughout the experiment, including the acclimation period and periods of elevated swimming speeds. $\dot{\mathrm{Mo}}_{2}$ was calculated from the slope of the decline in dissolved oxygen $\left(\mathrm{DO}_{2}\right)$ in the swim tunnel during each measurement period, omitting the first minute after closure of the valves. The closed period was extended to 15 to $20 \mathrm{~min}$ for the smaller yellowfin tuna. $\mathrm{DO}_{2}$ remained above $80 \%$ of air saturation levels throughout each experiment and was generally above $90 \%$ saturation except at high speeds. Temperature and oxygen content of the seawater in the swim tunnel were logged at 15-s intervals and $0.01 \mathrm{mg} \mathrm{L}^{-1}$ resolution by a Yellow Springs Instruments model 556 multiprobe. The $\mathrm{O}_{2}$ level within the swim tunnel dropped by 0.20 to $1.06 \mathrm{mg} \mathrm{L}^{-1}$ during each 10 -min closed period, depending on the size and activity level of the fish. The $\mathrm{O}_{2}$ electrode was calibrated in air-saturated seawater before and after each experiment, and the calibration was found to change by $<1 \%$ over the duration of the experiment.

Once metabolic rate measurements were initiated, the fish was allowed to acclimate to the respirometer for an additional 2-3 h while swimming at $1 \mathrm{BL} \mathrm{s}^{-1}$. The fish was then presented with a practice series of speed changes in which speed was increased in $0.15-\mathrm{BL} \mathrm{s}^{-1}$ increments during each flush period. This increment was reduced to $0.10 \mathrm{BL} \mathrm{s}^{-1}$ near the maximum speed of $1.8 \mathrm{BL} \mathrm{s}^{-1}$ (limited by the capacity of the swim tunnel motor). Following completion of this practice speed test, the speed was reduced to $1.0 \mathrm{BL} \mathrm{s}^{-1}$, and the fish was allowed to acclimate to the swim tunnel overnight for a minimum of 15 h. On the following day, speed was elevated or lowered in increments of 0.10 or $0.15 \mathrm{BL} \mathrm{s}^{-1}$, and a series of at least five consecutive $\dot{M}_{2}$ measurements was completed at each speed setting. Speed remained constant for a minimum of $100 \mathrm{~min}$ throughout the measurement and flush periods. Fish were maintained in the swim tunnel for a total of 2 to $6 \mathrm{~d}$. A $12 \mathrm{~L}: 12 \mathrm{D}$ cycle was maintained, matching the light cycle in the holding tanks. When all measurements were completed, the fish was removed from the swim tunnel in a water-filled sling, weighed on a scale with a damp cloth over its eyes, and returned to the holding tank. After each experiment, the swim tunnel was resealed and background respiration measured. In all cases, background respiration was negligible.

Figure 1 outlines a typical experiment and illustrates the decline of $\dot{M O}_{2}$ observed during the acclimation period. The $\dot{\mathrm{Mo}}_{2}$ values recorded at $1.0 \mathrm{BL} \mathrm{s}^{-1}$ immediately following the 15 -h acclimation period were $12 \%$ lower (paired $t$-test, $P<$ $0.05)$ than values recorded between 3 and $6 \mathrm{~h}$ postintroduction in the same fish. Control measurements of $\dot{M o}_{2}$ at $1.0 \mathrm{BL} \mathrm{s}^{-1}$ 


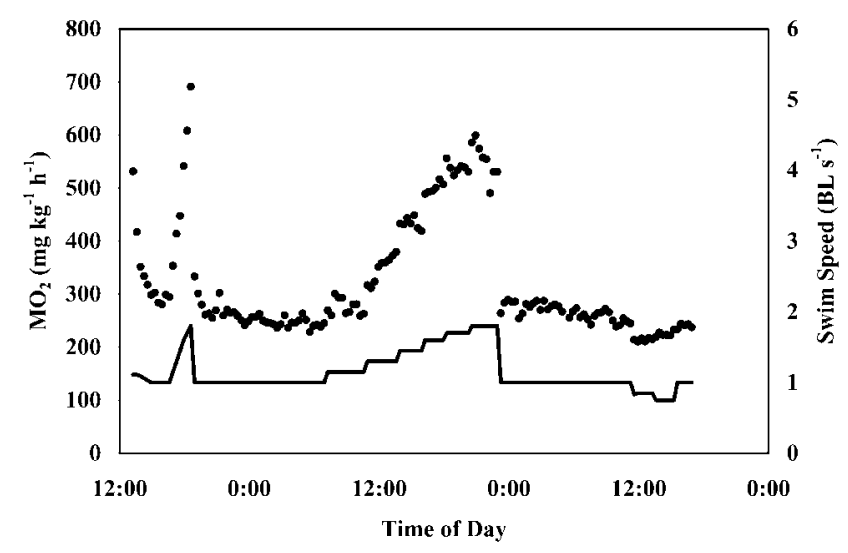

Figure 1. Time course of respirometry in a Pacific bluefin tuna. Closed system $\mathrm{MO}_{2}$ measurements (filled circles) were taken at 20-min intervals as the fish swam in an $870-\mathrm{L}$ swim tunnel at $20^{\circ} \mathrm{C}$ at controlled speeds indicated in BLs s${ }^{-1}$ (solid line). An overnight acclimation period preceded tests of speed effects on $\dot{\mathrm{Mo}}_{2}$.

following the series of speed changes reproduced $\mathrm{Mo}_{2}$ values recorded just after the initial acclimation period. Initial $\dot{\mathrm{Mo}}_{2}$ on sealing the respirometer was often higher, reaching $531 \mathrm{mg}$ $\mathrm{kg}^{-1} \mathrm{~h}^{-1}$ in one bluefin swimming at $1.11 \mathrm{BL} \mathrm{s}^{-1}$ (Fig. 1). Only data taken following the acclimation period were included in the subsequent analysis.

\section{Data Analysis}

While in the swim tunnel, the fish was monitored continuously via closed-circuit video, and any aberrant swimming behaviors or external disturbances resulting from noise, earthquakes, or building disturbances were noted. Individual measurements of $\dot{\mathrm{MO}}_{2}$ and other variables associated with disturbances were excluded from further analysis. The first $30 \mathrm{~min}$ of data following any change of speed were also excluded, and the mean of the remaining measurements at a given speed was taken as the $\dot{\mathrm{Mo}}_{2}$ for that speed (minimum of $\mathrm{N}=3$ ). Minimum swimming metabolic rates for each species were calculated from the mean $\dot{\mathrm{MO}}_{2}$ of each individual fish at the speed that minimized $\dot{\mathrm{Mo}}_{2}$ for that particular fish.

Tailbeat frequency (TBF) was measured by an observer watching the live video display of the swimming fish. Sixty tailbeats were timed with a stopwatch three times, and the computed tailbeats per minute from the three counts were averaged. This process was repeated at least twice for each fish at each speed. Results of initial tailbeat counts were confirmed by analysis of slow-motion video. Stride length, or distance traveled per tailbeat, was calculated as speed divided by TBF.

Except where otherwise indicated, comparisons between species were made on the basis of linear regressions relating log $\mathrm{MO}_{2}$, TBF, or stride length to swim speed for each species.
Significance was assessed at $P<0.05$. Data are presented as means $\pm \mathrm{SD}$.

\section{Results}

The mean metabolic rate of bluefin tuna swimming at $1 \mathrm{BL}$ $\mathrm{s}^{-1}$ at $20^{\circ} \mathrm{C}$ was $239 \pm 22 \mathrm{mg} \mathrm{kg}^{-1} \mathrm{~h}^{-1}(N=6$; Fig. $2 A$; Table 1). Measurements at swimming speeds of 0.75 to $1.8 \mathrm{BL} \mathrm{s}^{-1}$ yielded a J-shaped curve for $\dot{\mathrm{MO}}_{2}$ as a function of swimming speed. The lowest metabolic rates of swimming bluefin were $222 \pm 24 \mathrm{mg} \mathrm{kg}^{-1} \mathrm{~h}^{-1}$ at speeds of 0.75 to $1.0 \mathrm{BL} \mathrm{s}^{-1}$, and the maximum metabolic rates recorded in this study were $498 \pm$ $55 \mathrm{mg} \mathrm{kg}^{-1} \mathrm{~h}^{-1}$ at $1.80 \mathrm{BL} \mathrm{s}^{-1}$ (Fig. 2A). As speed was lowered from 1.0 $\mathrm{BL} \mathrm{s}^{-1}, \mathrm{Mo}_{2}$ increased in some fish and decreased in others (Fig. 2A). At the lowest speeds, the fish occasionally swam from side to side within the working section, sometimes bumping into the front and side walls when speed was too low.

A.

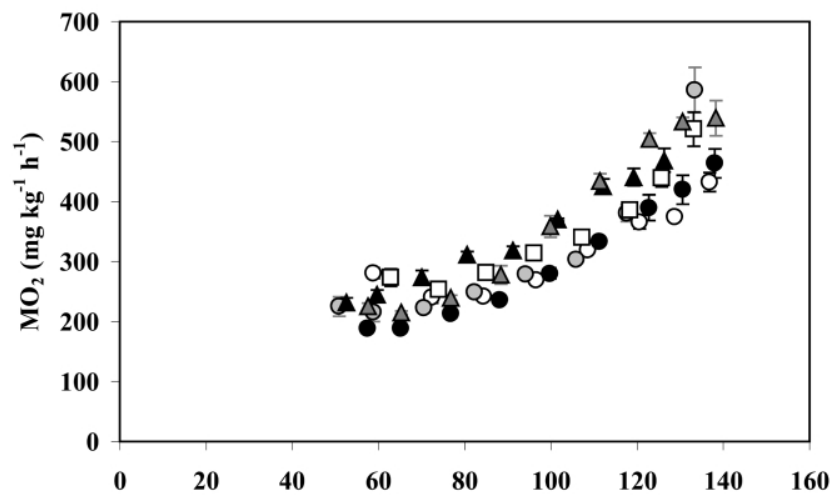

B. Swim Speed $\left(\mathrm{cm} \mathrm{s}^{-1}\right)$

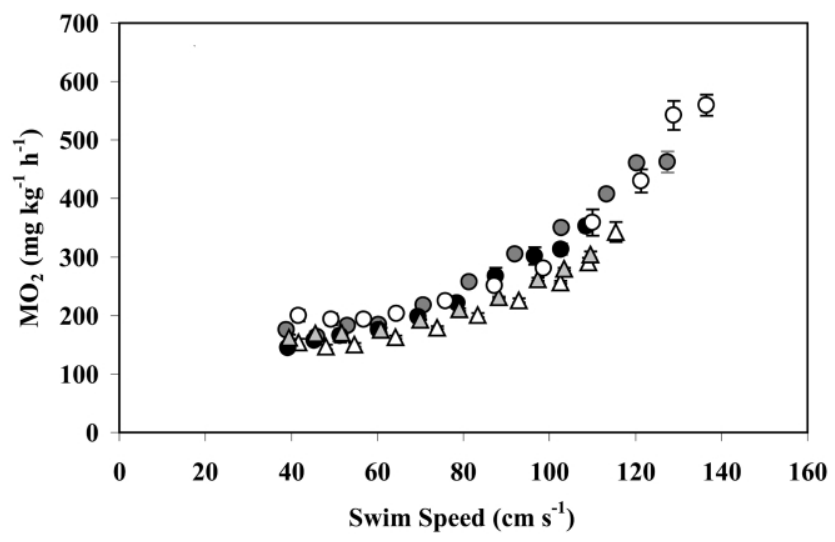

Figure 2. $\dot{\mathrm{Mo}}_{2}$-speed relationship in individual Pacific bluefin $(A)$ and yellowfin tuna $(B) . \mathrm{Mo}_{2}$ was measured as Pacific bluefin $(A$; mass $=$ $8.3 \pm 0.8 \mathrm{~kg}, N=6)$ and yellowfin $(B$; mass $=5.4 \pm 1.6 \mathrm{~kg}, N=5)$ swam in a swim-tunnel respirometer at speeds matched to the body length of each fish. Each point represents the mean \pm SD for at least four measurements of $\mathrm{Mo}_{2}$ of one fish at a given speed at $20.0^{\circ} \mathrm{C}$. Each individual fish is represented by a different shade or symbol. 
Table 1: Parameters of each least squares linear regression $(y=m \times U+b)$, relating $\log \dot{\mathrm{Mo}}_{2}$, tailbeat frequency $(\mathrm{TBF})$, or stride length $(\mathrm{SL})$ to swimming speed in Pacific bluefin and yellowfin tuna at $20^{\circ} \mathrm{C}$

\begin{tabular}{lcccc}
\hline Type and $x$ units & $n$ & $m$ & $b$ & $r^{2}$ \\
\hline Bluefin: & & & & \\
log $\mathrm{Mo}_{2}\left(\mathrm{mg} \mathrm{kg}^{-1} \mathrm{~h}^{-1}\right):$ & & & & \\
BL & 52 & .335 & 2.06 & .84 \\
cm & 52 & .0045 & 2.07 & .83 \\
TBF $\left(\mathrm{min}^{-1}\right):$ & & & & \\
BL & 34 & 70.7 & 46.1 & .87 \\
cm & 34 & .963 & 46.3 & .84 \\
SL: & & & & \\
BL & 34 & .165 & .34 & .66 \\
cm & 34 & .165 & 25.2 & .58 \\
Yellowfin: & & & & \\
log Mo ${ }_{2}\left(\mathrm{mg} \mathrm{kg}^{-1} \mathrm{~h}^{-1}\right):$ & & & & \\
BL & 52 & .327 & 1.98 & .72 \\
cm & 52 & .0053 & 1.96 & .88 \\
TBF $\left(\min ^{-1}\right):$ & & & & \\
BL & 50 & 60.3 & 43.0 & .90 \\
cm & 50 & .892 & 44.1 & .92 \\
SL: & & & & \\
BL & 50 & .209 & .36 & .79 \\
cm & 50 & .209 & 23.6 & .84 \\
\hline
\end{tabular}

Note. $\mathrm{BL}=$ body length; $n=$ number of observations.

Only four of six bluefin tuna swam at $0.75 \mathrm{BL} \mathrm{s}^{-1}$, and none swam consistently at $0.65 \mathrm{BL} \mathrm{s}^{-1}$.

Across the range of speeds tested, metabolic rates of bluefin tuna were significantly greater than those of yellowfin tuna swimming at the same relative speed (Fig. 3; $P<0.001$ ). The minimum $\dot{\mathrm{Mo}}_{2}$ of yellowfin was $162 \pm 19 \mathrm{mg} \mathrm{kg}^{-1} \mathrm{~h}^{-1}$ at speeds of 0.65 to $0.75 \mathrm{BL} \mathrm{s}^{-1}$, and $\dot{\mathrm{Mo}}_{2}$ increased to $405 \pm 105 \mathrm{mg}$ $\mathrm{kg}^{-1} \mathrm{~h}^{-1}$ at $1.8 \mathrm{BL} \mathrm{s}^{-1}$. Yellowfin tuna were able to swim at lower speeds than bluefin tuna, with all five yellowfin swimming steadily at $0.65 \mathrm{BL} \mathrm{s}^{-1}$ and two fish swimming at $0.55 \mathrm{BL} \mathrm{s}^{-1}$. As with the bluefin tuna, $\dot{M o}_{2}$ increased at the lowest swimming speed for some yellowfin; however, the minimum $\dot{M O}_{2}$ occurred at significantly lower speeds in yellowfin than in bluefin (Kruskal-Wallace, $P<0.05$ ). The minimum metabolic rate of bluefin tuna at $20^{\circ} \mathrm{C}$ was $37 \%$ higher than that of yellowfin.

TBFs of bluefin tuna were significantly higher than those of yellowfin tuna across the range of swimming speeds tested (Fig. $4 A$ ), regardless of whether swimming speed was expressed in body lengths per second or centimeters per second (Fig. 4A). TBF of bluefin tuna increased linearly from $99 \pm 7$ beats $\mathrm{min}^{-1}$ at $0.75 \mathrm{BL} \mathrm{s}^{-1}$ to $182 \pm 5$ beats $\mathrm{min}^{-1}$ at $1.80 \mathrm{BL} \mathrm{s}^{-1}$ as compared with $88 \pm 4$ beats $\min ^{-1}$ at $0.75 \mathrm{BL} \mathrm{s}^{-1}$ to $150 \pm 9$ beats $\mathrm{min}^{-1}$ at $1.80 \mathrm{BL} \mathrm{s}^{-1}$ in yellowfin tuna (Fig. $4 A$ ). Stride length (distance traveled per tailbeat) of bluefin tuna was significantly lower than that of yellowfin tuna at equivalent speeds (Fig. $4 B$ ). Bluefin stride length ranged from $0.46 \pm 0.04 \mathrm{BL}$ at $0.75 \mathrm{BL} \mathrm{s}^{-1}$ to $0.59 \pm 0.02 \mathrm{BL}$ at $1.80 \mathrm{BL} \mathrm{s}^{-1}$ (Fig. $4 B$ ). Stride length of yellowfin tuna increased from $0.42 \pm 0.02 \mathrm{BL}$ at $0.55 \mathrm{BL} \mathrm{s}^{-1}$ to $0.72 \pm 0.04 \mathrm{BL}$ at $1.80 \mathrm{BL} \mathrm{s}^{-1}$.

The gross cost of transport (GCOT) describes the metabolic cost for an animal to travel a given distance. GCOT was calculated by dividing the measured $\mathrm{Mo}_{2}$ by the speed at which it was recorded for each fish at each speed and converted into energetic units based on an oxycalorific coefficient of $14.1 \mathrm{~J}$ $\mathrm{mg} \mathrm{O}_{2}{ }^{-1}$ for oxidation of a mixture of protein, fat, and carbohydrate (Videler 1993). GCOT of bluefin tuna reached a minimum at $1.23 \mathrm{~J} \mathrm{~kg}^{-1} \mathrm{~m}^{-1}$ at 1.15 and $1.3 \mathrm{BL} \mathrm{s}^{-1}$ and increased at higher and lower speeds (Fig. 5). GCOT of yellowfin tuna showed a similar pattern, reaching a minimum of $1.10 \mathrm{~J}$ $\mathrm{kg}^{-1} \mathrm{~m}^{-1}$ at 1.15 and $1.3 \mathrm{BL} \mathrm{s}^{-1}$. GCOT at a given speed (in $\mathrm{BL} \mathrm{s}^{-1}$ ) was significantly greater in bluefin tuna than in yellowfin tuna (paired $t$-test, $P<0.0001$ ).

SMRs of tunas and other obligate ram ventilators have often been calculated by plotting the relationship between log $\dot{M o}_{2}$ and swimming speed and extrapolating to 0 velocity (Brett 1964; Gooding et al. 1981). Applying this calculation to individual fish yielded mean SMRs of $120 \pm 26 \mathrm{mg} \mathrm{kg}^{-1} \mathrm{~h}^{-1}$ for bluefin and $91 \pm 13 \mathrm{mg} \mathrm{kg}^{-1} \mathrm{~h}^{-1}$ for yellowfin tuna.

\section{Discussion}

This study reports measurements of metabolic rates of juvenile Pacific bluefin tuna Thunnus orientalis and yellowfin tuna Thunnus albacares swimming in a swim-tunnel respirometer. Bluefin $\dot{\mathrm{MO}}_{2}$ was significantly greater than $\dot{\mathrm{Mo}}_{2}$ of yellowfin tuna swimming at equivalent speeds using the same protocol.

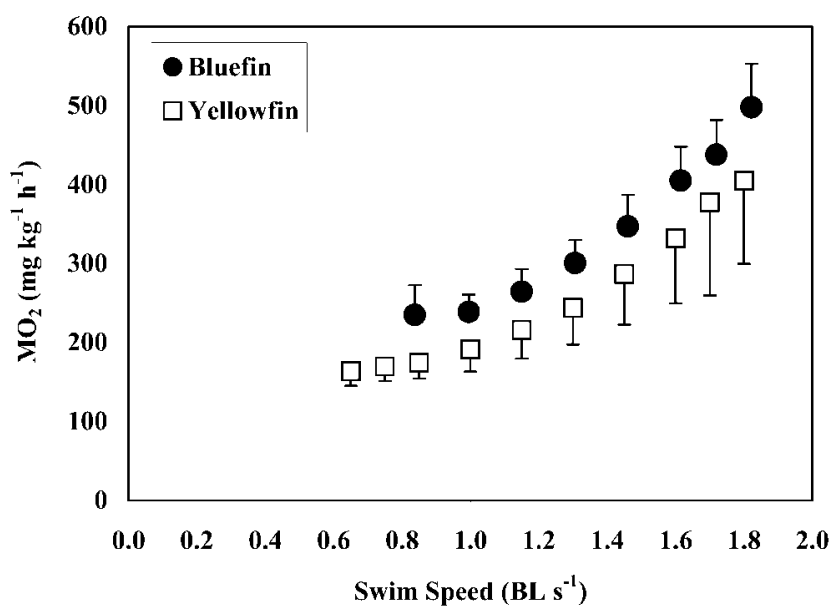

Figure 3. $\dot{\mathrm{MO}}_{2}$ of swimming Pacific bluefin and yellowfin tunas. $\dot{\mathrm{MO}}_{2}$ was measured as the fish swam in an 870-L swim-tunnel respirometer at $20^{\circ} \mathrm{C}$. Each point represents the mean $\pm \mathrm{SD}$ of $\mathrm{Mo}_{2}$ of six bluefin tuna (filled circles; mass $=8.3 \pm 0.8 \mathrm{~kg}$ ) or five yellowfin tuna (open squares; mass $=5.4 \pm 1.6 \mathrm{~kg}$ ). 

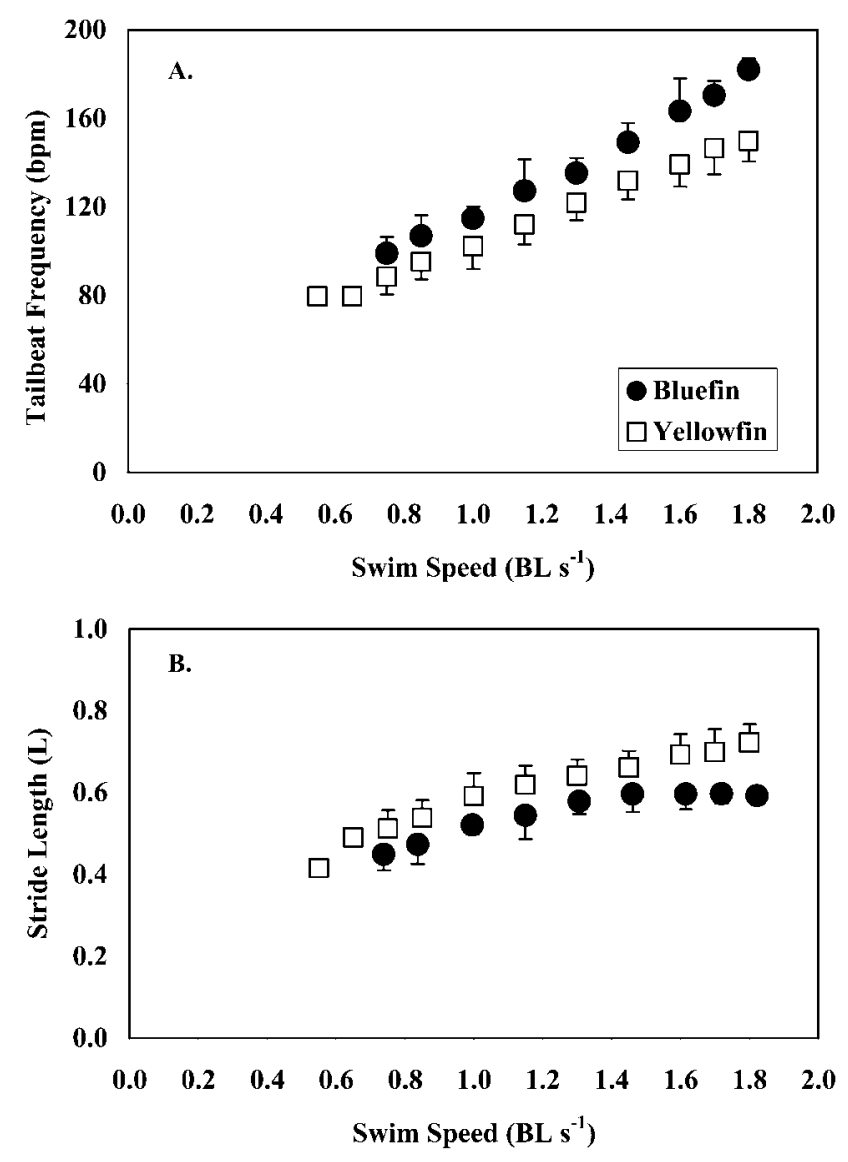

Figure 4. Tailbeat frequency $(A)$ and stride length $(B)$ of Pacific bluefin (filled circles) and yellowfin tuna (open squares). Each data point represents the mean \pm SD of values obtained from at least two fish swimming at speeds matched to individual body length. Stride lengths are expressed as fractions of the body length of each individual fish.

The two species were collected in an area where their ranges seasonally overlap along the western coast of North America and held in the same tanks before experiments. The higher metabolic rates of bluefin tuna compared with yellowfin are in accord with other indicators of physiological performance in the two species. Bluefin have warmer tissues, greater relative heart masses, higher heart rates and cardiac outputs, and higher concentrations of cardiac $\mathrm{Ca}^{2+}$ cycling proteins than yellowfin tuna (Carey and Lawson 1973; Poupa et al. 1981; Blank et al. 2002, 2004; Landeira-Fernandez et al. 2004). Both cellular and organismal traits indicate that higher metabolic rates have evolved specifically in this cold-temperate lineage of Thunnus.

The minimum metabolic rates of $222 \pm 24 \mathrm{mg} \mathrm{kg}^{-1} \mathrm{~h}^{-1}$ recorded in fasted, bluefin tuna swimming at 0.75 to $1.0 \mathrm{BL}$ $\mathrm{s}^{-1}$ were lower than those previously published for other species of tuna. The use of a large swim tunnel made it possible to record metabolic rates of swimming fish at controlled speeds and temperatures for up to six consecutive days. This duration of metabolic measurements is unprecedented for tunas. Overnight acclimation allowed the fish to recover from handling stress and oxygen debt that are associated with introduction of fish to swim tunnels (Sepulveda et al. 2003) and produced significant declines in metabolic rate (Fig. 1). Similar results have been noted by other investigators working on a variety of species, including salmonids and cod (Brett 1964; Steffensen et al. 1994).

\section{Comparison of Tailbeat Frequency between Species}

TBFs of bluefin were 10\%-17\% higher than those of yellowfin tuna at equivalent swimming speeds measured in $\mathrm{BL} \mathrm{s}{ }^{-1}$ (Fig. $4 A$ ). The higher TBF in bluefin is likely to increase oxygen demand of the working muscle mass and contribute directly to higher metabolic rates at a given swimming speed. A higher $\mathrm{TBF}$ at routine swimming speeds would also increase heat production within the slow-twitch muscle and contribute to the elevation of muscle temperature in bluefin tuna. Dewar et al. (1994) recorded a similar effect in yellowfin tuna, as acute increases in swimming speed increased both TBF and slowtwitch muscle temperatures. Conversely, higher muscle temperatures increase the frequencies at which power output and efficiency of the muscle are optimized (Altringham and Block 1997). The causal relationships between heat conservation, muscle temperature, TBF, and oxygen consumption during swimming and the dependence of these factors on ontogeny and body size require further study.

TBFs measured in both bluefin and yellowfin tunas in this study were lower than those previously recorded in yellowfin and skipjack tunas swimming at similar relative speeds in a flume (Dewar and Graham 1994b; Knower et al. 1999). This

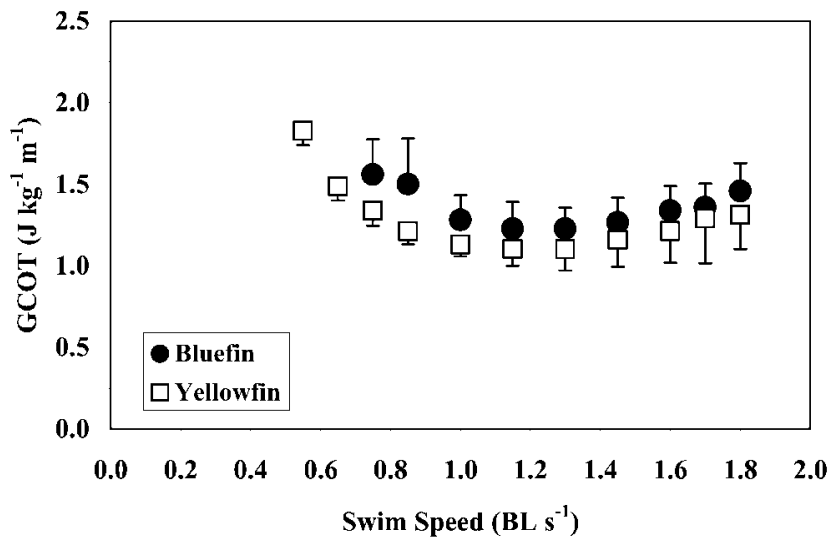

Figure 5. Gross cost of transport (GCOT) in Pacific bluefin tuna (filled circles) and yellowfin tuna (open squares). GCOT was calculated by dividing $\mathrm{Mo}_{2}$ by swim speed and applying a conversion factor of 14.1 $\mathrm{J} \mathrm{mg}^{-1} \mathrm{O}_{2}^{-1}$. Each point represents the mean GCOT $\pm \mathrm{SD}$ for $N=$ 6 bluefin $\left(N=4\right.$ at $\left.0.75 \mathrm{BL} \mathrm{s}^{-1}\right)$ or $N=5$ yellowfin $(N=2$ at 0.55 $\left.\mathrm{BL} \mathrm{s}{ }^{-1}\right)$ at a given speed at $20.0^{\circ} \mathrm{C}$. 
difference may be a scaling effect, given the larger size of the fish used in this study. TBF at a given speed is inversely related to body size in fish utilizing caudal fin propulsion (Webb et al. 1984).

Minimal metabolic rates of bluefin tuna were $37 \%$ higher than those of yellowfin tuna and occurred at significantly higher relative speeds in bluefin $\left(0.75-1.0 \mathrm{BL} \mathrm{s}^{-1}\right)$ than in yellowfin tuna (0.65-0.75 BL s${ }^{-1}$; Figs. 2, 3). The inability of bluefin to swim efficiently at low speeds may be associated with the distinct differences in pectoral fin surface area between the two species. Yellowfin have larger pectoral fins that produce more lift at a given speed, which may permit them to maintain vertical station at lower swimming speeds (Magnuson 1973). The smaller pectoral fins of the bluefin may constrain them to maintain higher speeds and TBFs during routine cruising, thereby increasing minimum metabolic rate. The capacity to use the larger pectoral fins for increased lift may play a role in the reduction of metabolic costs in yellowfin in comparison to bluefin tuna.

\section{Cost of Transport}

Calculations of gross cost of transport at a range of speeds can be used to determine optimal swimming speed $\left(U_{\text {opt }}\right)$ at which the energy cost to cover a given distance is minimized (Tucker 1970). GCOT of bluefin tuna reached minimum values of 1.23 $\mathrm{J} \mathrm{kg}^{-1} \mathrm{~m}^{-1}$ at 1.15 to $1.30 \mathrm{BL} \mathrm{s}^{-1}$ (Fig. 5). This speed range is similar to mean swimming speeds of Pacific bluefin tuna in the wild $(80-120 \mathrm{~cm})$, as calculated from acoustic track records (Marcinek et al. 2001). GCOT of yellowfin tuna was minimized at $1.10 \mathrm{~J} \mathrm{~kg}^{-1} \mathrm{~m}^{-1}$ at the same relative speeds as in bluefin (Fig. 4). GCOT across the range of speeds tested was significantly greater in bluefin tuna than yellowfin tuna. This difference reflects the difference in $\dot{M o}_{2}$ between species and may be related to the higher TBF employed by the bluefin tuna.

GCOT values at $\mathrm{U}_{\text {opt }}$ for both bluefin and yellowfin tuna were lower than indicated in previous studies of yellowfin tuna (Dewar and Graham 1994a) and lower than published values for GCOT of bonito and mackerel (Dickson et al. 2002; Sepulveda et al. 2003). This difference can be explained in part by differences in body size, as GCOT scales negatively relative to body mass (Videler 1993). GCOT at $\mathrm{U}_{\mathrm{opt}}$ for tuna was approximately twofold higher than predicted by allometric equations describing swimming costs in a wide range of teleosts (Videler 1993). In both tuna species, GCOT increased relatively little with moderate speed increases, suggesting that tunas undertaking long migrations are able to select from a range of speeds without suffering a substantial energetic penalty. While the increased GCOT at low speeds primarily reflects the greater share of nonlocomotor costs in total metabolic rate, it may also be overestimated in a swim-tunnel setting, as the length of the working section constrains the fish to swim at a constant speed without coasting (Korsmeyer and Dewar 2001).

\section{Effects of Body Size and Experimental Temperature}

Mass-specific metabolic rates of both bluefin and yellowfin tunas recorded in this study were lower than those previously published for yellowfin and skipjack tunas. These differences can be attributed in part to scaling and temperature effects. Most previous studies of yellowfin tuna, skipjack, and kawakawa employed juvenile fish of $0.5-4.0 \mathrm{~kg}$. Scaling exponents of approximately 0.6 for SMRs of yellowfin and skipjack tuna have been empirically determined using immobilized fish (Brill 1979, 1987) and fish swimming in a swim tunnel (Dewar and Graham 1994a), although scaling exponents $>1.0$ have been reported in some other studies (Gooding et al. 1981; Graham et al. 1989). Application of scaling exponents determined in juvenile tunas to larger fish is complicated by the unknown influence of increasing body size on heat conservation and internal body temperatures. Interspecific scaling exponents of $\sim 0.8$ have been reported for a broader array of teleosts (Clarke and Johnston 1999). The size difference between the bluefin $(8.3 \pm 0.8 \mathrm{~kg})$ and yellowfin $(5.4 \pm 1.6 \mathrm{~kg})$ tuna in this study may result in an underestimation of the difference in metabolic rate between species, as the smaller size of the yellowfin would be expected to produce a higher mass-specific metabolic rate, contrary to our findings.

Previous studies on yellowfin and skipjack tuna have primarily been conducted at $25^{\circ} \mathrm{C}$, whereas tunas in this study were maintained and tested at $20^{\circ} \mathrm{C}$. Both species commonly encounter $20^{\circ} \mathrm{C}$ waters in the eastern Pacific (Block et al. 1997; Marcinek et al. 2001), and the fish used in this study were captured in waters with a sea-surface temperature of $20^{\circ} \mathrm{C}$. Dewar and Graham (1994a) report a $\mathrm{Q}_{10}$ of 1.67 for acute temperature changes in the range $18^{\circ}-30^{\circ} \mathrm{C}$ in small yellowfin tuna swimming at constant speed, and preliminary results suggest a similar $\mathrm{Q}_{10}$ for metabolic rate of bluefin tuna at $20^{\circ}$ $25^{\circ} \mathrm{C}$ (J. M. Blank, J. M. Morrissette, C. J. Farwell, M. Price, R. J. Schallert, and B. A. Block, unpublished data). However, $\mathrm{Q}_{10}$ values based on acute temperature change may be inappropriate for correcting comparisons between studies in which fish have been acclimated to the temperatures at which they are tested. Acclimation before measurement would tend to mitigate the effects of the acute temperature difference so that applying a $\mathrm{Q}_{10}$ based on an acute temperature change would result in overcorrection.

If corrections for body size $(b=0.6)$ and temperature $\left(\mathrm{Q}_{10}=1.67\right)$ are applied, $\dot{\mathrm{Mo}}_{2}$ of swimming yellowfin tuna measured in this study remains approximately $20 \%$ lower than the lowest published measurements of $\mathrm{Mo}_{2}$ in swimming yellowfin (Dewar and Graham 1994a). The SMR of yellowfin in this study, as calculated by extrapolating $\dot{M O}_{2}$-speed relationships to 0 velocity and corrected for mass and temperature, was $16 \%$ lower than the SMR measured in spinally blocked yellowfin (Brill 1987) and 33\% lower than that previously calculated for swimming fish (Dewar and Graham 1994a). These 
remaining differences in metabolic rate are likely to result from differences in experimental protocols between studies.

\section{Influence of Experimental Protocols and Fasting}

The experimental protocol used in this study was intended to overcome the difficulties of measuring $\dot{M}_{2}$ in an obligate ram ventilator and produce measurements of minimum metabolic rates of swimming tuna. In order to ensure a postabsorptive state before metabolic measurements, all tuna used in the study were fasted for 45-72 $\mathrm{h}$ before introduction to the swim tunnel. The captive tuna were routinely fed three times per week and were accustomed to feeding at 48-72-h intervals. Although gastric emptying may take $12 \mathrm{~h}$ or less in skipjack tuna, digestion often continues in the pyloric caeca and intestine for longer periods (Magnuson 1969). Both wild and captive bluefin tuna display substantial postfeeding increases in visceral temperature, which can be used as indicators of the duration of digestive processes (Carey et al. 1984; Gunn et al. 2001). Electronic tagging has shown that stomach and peritoneal cavity temperatures of captive bluefin can remain elevated for over $40 \mathrm{~h}$ following feeding (Carey et al. 1984; Gunn et al. 2001) and are routinely elevated for up to $36 \mathrm{~h}$ in captive fish identical in size and feeding regimen to those used in these experiments (Farwell 2001). This suggests that the 2-d fasting period was essential in eliminating the effects of specific dynamic action on metabolic rate in these experiments. Wild Pacific bluefin tuna carrying archival tags often forage daily, recording significant increases in visceral temperature following feeding. However, temperature records from archival tags demonstrate that involuntary fasting periods are also common and are not limited to migration and breeding periods (Kitagawa et al. 2004).

In addition to fasting, overnight acclimation and the precautions taken to reduce traffic and noise in the laboratory may have resulted in lower measured metabolic rates. In a few cases, fish were visibly startled by unintended disturbances such as noise, lighting changes, power surges, and an earthquake, elevating the measured $\dot{M O}_{2}$ and confirming the importance of these precautions.

\section{Comparison of Standard Metabolic Rates among Species}

Because tunas are obligate ram ventilators, it is common to calculate SMRs by measuring metabolic rate at a range of swimming speeds and then extrapolating the curve relating metabolic rate and speed to 0 velocity (Brett 1964; Gooding et al. 1981). This method yielded mean SMRs for bluefin and yellowfin tunas of $120 \pm 26$ and $91 \pm 13 \mathrm{mg} \mathrm{kg}^{-1} \mathrm{~h}^{-1}$, respectively. This calculation has been criticized on both theoretical and practical grounds as potentially misrepresenting SMR due to error in extrapolation and metabolic trade-offs encountered during exercise (Thorarensen et al. 1993; Farrell et al. 2003). The increase in metabolic rate observed at low speeds in several of the fish studied here suggests that the minimum metabolic rate of swimming tuna may be a more physiologically relevant measure than SMR at 0 velocity. However, SMR may provide a useful point of comparison with the published literature. After correction to $25^{\circ} \mathrm{C}$ and normalization to a standard mass, SMR of yellowfin tuna in this study remains $20 \%-50 \%$ lower than published values for yellowfin (Brill 1987; Dewar and Graham 1994a). This difference may reflect the experimental protocol and the long fasting and acclimation periods used to avoid artificial elevation of metabolic rates in this study.

The calculated SMR of bluefin tuna is significantly greater than that of yellowfin tuna in this study and, if corrected for body mass based on allometric predictions, exceeds SMRs reported for ectothermic scombrids (Dickson et al. 2002; Sepulveda et al. 2003). Bluefin SMR is 50\%-120\% higher than that of bonito and $100 \%$ to severalfold higher than that of mackerel, depending on whether a scaling exponent of 0.6 or 0.8 is applied. However, the mass-specific SMRs calculated for bluefin and yellowfin at $20^{\circ} \mathrm{C}$ are similar to those of bonito and mackerel at $18^{\circ} \mathrm{C}$, and any comparisons should be interpreted with caution due to the large differences in body size between species and studies.

\section{Implications to Physiology and Ecology of Tuna}

This article demonstrates that metabolic rates of swimming bluefin tuna are higher than those of yellowfin tuna. Metabolic rate data are important to understanding the energetics and ecology of tuna populations in the wild and provide additional information on how Pacific bluefin tuna diverge from other tunas. Recent work indicates that bluefin have higher heart rates and cardiac outputs than yellowfin, which may be related to higher levels of cardiac sarcoplasmic reticulum $\mathrm{Ca}^{2+}$ ATPase (Blank et al. 2004; Landeira-Fernandez et al. 2004). These cellular and organ traits of bluefin can now be linked to higher metabolic rates in vivo, suggesting that increased cellular $\mathrm{Ca}^{2+}$ cycling capacity may underlie whole-animal metabolic performance. This pattern of high metabolic rates co-occurring with high levels of cardiac performance and robust cardiac sarcoplasmic reticulum $\mathrm{Ca}^{2+}$ cycling appears in a broad range of teleosts as well as in mammals and birds (Hamilton and Ianuzzo 1991; Vornanen et al. 2002), supporting a linkage between excitation-contraction coupling in cardiac cells, increased cardiac output, and higher metabolic rates. Previous hypotheses linking the evolution of high metabolic rates in tunas to increased expression of intracellular cardiac excitation-contractioncoupling proteins were based largely on comparisons of tunas to ectothermic scombrid fishes (Blank et al. 2004). This study provides the metabolic data to link cardiac myocyte function, oxygen delivery, and metabolism in an endothermic fish.

The higher metabolic rates of bluefin tuna compared with yellowfin are correlated with cold tolerance and a greater ca- 
pacity for endothermy in bluefin. Bluefin tuna maintain higher slow-twitch muscle temperatures and larger thermal excesses than yellowfin tuna of a given body size (Barrett and Hester 1964; Carey and Teal 1969; Marcinek et al. 2001). Aerobic enzyme activities in the atrium, ventricle, and skeletal muscle are similar across different Thunnus species when measured in vitro (Dickson 1996; Marcinek 2000; Blank et al. 2004). However, the higher temperatures in slow-twitch muscle of bluefin would increase aerobic enzyme activities in vivo, increasing the potential oxygen consumption of bluefin skeletal muscle (Marcinek et al. 2001). It has been reported that oxidative slowtwitch muscle comprises a larger proportion of the body mass in bluefin than in yellowfin (Kishinouye 1923), although comparisons are complicated by the differences in body size of specimens (Sharp and Pirages 1978). A larger mass of oxidative red muscle would tend to increase oxygen consumption and heat production in bluefin relative to yellowfin.

In addition to the lateral retia, which conserve heat in the skeletal muscle, bluefin have well-developed countercurrent retia mirabilia associated with the stomach and caecum (Carey and Lawson 1973; Block et al. 2001). These visceral heat exchangers allow Pacific bluefin to elevate visceral temperature following feeding and maintain this temperature elevation for many hours (Farwell 2001) whereas yellowfin tuna inhabiting the same waters exhibit no significant visceral thermal excess (K. M. Schaefer, D. W. Fuller, and B. A. Block, unpublished data). Visceral temperatures would be minimized by the long fasting periods preceding $\mathrm{Mo}_{2}$ measurements (Carey et al. 1984; Gunn et al. 2001); however, bluefin of the size used in this study maintain baseline peritoneal cavity temperatures $1^{\circ}-2^{\circ} \mathrm{C}$ above ambient following fasting (Farwell 2001; Kitagawa et al. 2004), which may increase the oxygen demand of the viscera. Collectively, differences in tissue temperatures between bluefin and yellowfin may explain much of the difference in oxygen consumption between species. The ability of bluefin tuna to maintain large thermal gradients between oxidative tissues and ambient water has allowed the species to expand its thermal niche into productive subpolar waters. The elevated metabolic rates presented here may be an essential component of the thermoregulatory capacity of bluefin. While high rates of oxidative metabolism contribute to maintenance of muscle and visceral tissues at optimal temperatures, they can do little to warm the heart, which must function at ambient temperature. Thus, the cardiac specializations for intracellular EC-coupling that sustain high cardiac outputs and high metabolic rates in bluefin tuna are also essential for cold tolerance and thermalniche expansion.

The high aerobic capacity of tuna has been described as an adaptation for dealing with multiple simultaneous metabolic demands (Korsmeyer et al. 1996). The finding that minimum metabolic rates of swimming yellowfin are lower than previously reported helps to explain how tuna can superimpose the energetic demands of constant swimming, feeding, digestion, growth, and recovery from burst swimming. These measurements should improve our ability to model the energetics of tuna in the field and understand the balance between these competing demands in wild individuals and populations. Under most circumstances, field metabolic rates of both bluefin and yellowfin are likely to be substantially higher than metabolic rates reported here due to these additional energetic demands. The influence of ambient temperature and thermogenic physiological processes such as specific dynamic action on metabolic rates of tunas is of particular interest. The impact of these factors may be especially large in tunas due to coordinate increases in body temperatures and metabolic rate with increasing feeding and swimming activity (Carey et al. 1984; Dewar et al. 1994). Clarifying the influence of body size, ambient temperature, feeding status, and behavior on the metabolic rates of tuna and other scombrids remains an important goal.

\section{Acknowledgments}

This project was supported by National Science Foundation grant IBN-0215272 and the Monterey Bay Aquarium Foundation. The fish were acquired with the assistance of the captain and crew of the F/V Shogun and the husbandry department of the Monterey Bay Aquarium. The control room staff of the Montery Bay Aquarium, Eric Kingsley, Wayne Sperduto, and John Lee provided troubleshooting and operations expertise. Alex Norton, Matthew Price, Tom Williams, Siobhan Coughlin, Andre Boustany, and Steve Teo provided expert assistance with experimental procedures.

\section{Literature Cited}

Altringham J.D. and B.A. Block. 1997. Why do tuna maintain elevated slow muscle temperatures? power output of muscle isolated from endothermic and ectothermic fish. J Exp Biol 200:2617-2627.

Barrett I. and F.J. Hester. 1964. Body temperature of the yellowfin and skipjack tunas in relation to sea surface temperature. Nature 203:96-97.

Bell W.H. and L.D.B. Terhune. 1970. Water tunnel design for fisheries research. Can Fish Res Board Tech Rep 195:1-69.

Blank J.M., J.M. Morrissette, P.S. Davie, and B.A. Block. 2002. Effects of temperature, epinephrine and $\mathrm{Ca}^{2+}$ on the hearts of yellowfin tuna (Thunnus albacares). J Exp Biol 205:18811888.

Blank J.M., J.M. Morrissette, A.M. Landeira-Fernandez, S.B. Blackwell, T.D. Williams, and B.A. Block. 2004. In situ cardiac performance of Pacific bluefin tuna hearts in response to acute temperature change. J Exp Biol 207:881-890.

Block B.A., H. Dewar, S.B. Blackwell, T.D. Williams, E.D. Prince, C.J. Farwell, A. Boustany, et al. 2001. Migratory 
movements, depth preferences, and thermal biology of Atlantic bluefin tuna. Science 293:1310-1314.

Block B.A., J.E. Keen, B. Castillo, H. Dewar, E.V. Freund, D.J. Marcinek, R.W. Brill, and C. Farwell. 1997. Environmental preferences of yellowfin tuna (Thunnus albacares) at the northern extent of its range. Mar Biol 130:119-132.

Block B.A., S.L.H. Teo, A. Walli, A. Boustany, M.J.W. Stokesbury, C.J. Farwell, K.C. Weng, H. Dewar, and T.D. Williams. 2005. Electronic tagging and population structure of Atlantic bluefin tuna. Nature 28:1121-1127.

Boggs C.H. and J.F. Kitchell. 1991. Tuna metabolic rates estimated from energy losses during starvation. Physiol Zool 64: 502-524.

Brett J.R. 1964. The respiratory metabolism and swimming performance of young sockeye salmon. J Fish Res Board Can 21:1183-1226.

Brill R.W. 1979. The effect of body size on the standard metabolic rate of skipjack tuna, Katsuwonus pelamis. Fish Bull 77:494-498.

-1987. On the standard metabolic rates of tropical tunas, including the effect of body size and acute temperature change. Fish Bull 85:25-35.

Brill R.W. and P.G. Bushnell. 2001. The cardiovascular system of tunas. Pp. 79-120 in B.A. Block and E.D. Stevens, eds. Tunas: Physiology, Ecology and Evolution. Academic Press, San Diego, CA.

Carey F.G., J.W. Kanwisher, and E.D. Stevens. 1984. Bluefin tuna warm their viscera during digestion. J Exp Biol 109:120.

Carey F.G. and K.D. Lawson. 1973. Temperature regulation in free-swimming bluefin tuna. Comp Biochem Physiol A 44: 375-392.

Carey F.G. and J.M. Teal. 1969. Regulation of body temperature by the bluefin tuna. Comp Biochem Physiol 28:205-213.

Clarke A. and N.M. Johnston. 1999. Scaling of metabolic rate with body mass and temperature in teleost fish. J Anim Ecol 68:893-905.

Dewar H. and J.B. Graham. 1994a. Studies of tropical tuna swimming performance in a large water tunnel. 1. Energetics. J Exp Biol 192:13-31.

-1994b. Studies of tropical tuna swimming performance in a large water tunnel. 3. Kinematics. J Exp Biol 192:4559.

Dewar H., J.B. Graham, and R.W. Brill. 1994. Studies of tropical tuna swimming performance in a large water tunnel. 2. Thermoregulation. J Exp Biol 192:33-44.

Dickson K. 1996. Locomotor muscle of high performance fishes: what do comparisons of tunas with ectothermic sister taxa reveal? Comp Biochem Physiol A 113:39-49.

Dickson K.A., J.M. Donley, C. Sepulveda, and L. Bhoopat. 2002. Effects of temperature on sustained swimming performance and swimming kinematics of the chub mackerel Scomber japonicus. J Exp Biol 205:969-980.
Farrell A.P., P.S. Davie, C.E. Franklin, J.A. Johansen, and R.W. Brill. 1992. Cardiac physiology in tunas. 1. In vitro perfused heart preparations from yellowfin and skipjack tunas. Can J Zool 70:1200-1210.

Farrell A.P., C.G. Lee, K. Tierney, A. Hodaly, S. Clutterham, M. Healey, S. Hinch, and A. Lotto. 2003. Field-based measurements of oxygen uptake and swimming performance with adult Pacific salmon using a mobile respirometer swim tunnel. J Fish Biol 62:64-84.

Farwell C.J. 2001. Tunas in captivity. Pp. 391-412 in B.A. Block and E.D. Stevens, eds. Tunas: Physiology, Ecology and Evolution. Academic Press, San Diego, CA.

Fierstine H.L. and V. Walters. 1968. Studies in locomotion and anatomy of scombroid fishes. Mem South Calif Acad Sci 6: $1-31$.

Freund E. 1999. Comparisons of metabolic and cardiac performance in scombrid fishes: insights into the evolution of endothermy. PhD diss. Stanford University, Palo Alto, CA.

Giovane A., G. Greco, A. Maresca, and B. Tota. 1980. Myoglobin in the heart ventricle of tuna and other fishes. Experientia 36:219-220.

Gooding R.M., W.H. Neill, and A.E. Dizon. 1981. Respiration rates and low oxygen tolerance limits in skipjack tuna, Katsuwonus pelamis. Fish Bull 79:31-48.

Graham J.B. and R.M. Laurs. 1982. Metabolic rate of the albacore tuna Thunnus alalunga. Mar Biol 72:1-6.

Graham J.B., W.R. Lowell, N.C. Lai, and R.M. Laurs. 1989. O, tension, swimming-velocity, and thermal effects on the metabolic rate of the pacific albacore Thunnus alalunga. Exp Biol 48:89-94.

Gunn J., J. Hartog, and K. Rough. 2001. The relationship between food intake and visceral warming in southern bluefin tuna (Thunnus maccoyii). Pp. 109-130 in J.R. Sibert and J.L. Nielsen, eds. Electronic Tagging and Tracking in Marine Fishes. Kluwer Academic, Dordrecht.

Guppy M., W.C. Hulbert, and P.W. Hochachka. 1979. Metabolic sources of heat and power in tuna muscles. II. Enzyme and metabolite profiles. J Exp Biol 82:303-320.

Hamilton N. and C. Ianuzzo. 1991. Contractile and calcium regulating capacities of myocardia of different sized mammals scale with resting heart rate. Mol Cell Biochem 106: 133-141.

Hughes G.M. 1984. General anatomy of the gills. Pp. 1-72 in W.S. Hoar and D.J. Randall, eds. Fish Physiology. Vol. 10. Gills, Part A: Anatomy, Gas Transfer, and Acid-Base Regulation. Academic Press, New York.

Kishinouye K. 1923. Contributions to the comparative study of the so-called scombroid fishes. J Coll Agric Imp Univ Tokyo 8:293-475.

Kitagawa T., S. Kimura, H. Nakata, and H. Yamada. 2004. Diving behavior of immature, feeding Pacific bluefin tuna (Thunnus thynnus orientalis) in relation to season and area: 
the East China Sea and the Kuroshio-Oyashio transition region. Fish Oceanogr 13:161-180.

. 2006. Thermal adaptation of Pacific bluefin tuna Thunnus orientalis to temperate waters. Fish Sci 72:149-156.

Kitagawa T., H. Nakata, S. Kimura, T. Sugimoto, and H. Yamada. 2002. Differences in vertical distribution and movement of Pacific bluefin tuna (Thunnus thynnus orientalis) among areas: the East China Sea, the Sea of Japan and the western North Pacific. Mar Freshw Res 53:245-252.

Knower T., R.E. Shadwick, S.L. Katz, J.B. Graham, and C.S. Wardle. 1999. Red muscle activation patterns in yellowfin (Thunnus albacares) and skipjack (Katsuwonus pelamis) tunas during steady swimming. J Exp Biol 202:2127-2138.

Korsmeyer K.E. and H. Dewar. 2001. Tuna metabolism and energetics. Pp. 35-78 in B.A. Block and E.D. Stevens, eds. Tunas: Physiology, Ecology and Evolution. Academic Press, San Diego, CA.

Korsmeyer K.E., H. Dewar, N.C. Lai, and J.B. Graham. 1996. The aerobic capacity of tunas: adaptation for multiple metabolic demands. Comp Biochem Physiol A 113:17-24.

Landeira-Fernandez A.M., J.M. Morrissette, J.M. Blank, and B.A. Block. 2004. Temperature dependence of the $\mathrm{Ca}^{2+}$ ATPase (SERCA2) in the ventricles of tuna and mackerel. Am J Physiol 286:R398-R404.

Linthicum D.S. and F.G. Carey. 1972. Regulation of brain and eye temperatures by the bluefin tuna. Comp Biochem Physiol A 43:425-433.

Magnuson J.J. 1969. Digestion and food consumption by skipjack tuna (Katsuwonus pelamis). Trans Am Fish Soc 98:379392

1973. Comparative study of adaptations for continuous swimming and hydrostatic equilibrium of scombroid and xiphoid fishes. Fish Bull 71:337-356.

Marcinek D.J. 2000. The physiological ecology of myoglobin in scombrid fish. PhD diss. Stanford University, Palo Alto, CA.

Marcinek D.J., S.B. Blackwell, H. Dewar, E.V. Freund, C. Farwell, D. Dau, A.C. Seitz, and B.A. Block. 2001. Depth and muscle temperature of Pacific bluefin tuna examined with acoustic and pop-up satellite archival tags. Mar Biol 138: 869-885.

Modigh M. and B. Tota. 1975. Mitochondrial respiration in the ventricular myocardium and in the white and deep red myotomal muscles of juvenile tuna fish (Thunnus thynnus L.). Acta Physiol Scand 93:289-294.

Moyes C.D., O.A. Mathieu-Costello, R.W. Brill, and P.W. Hochachka. 1992. Mitochondrial metabolism of cardiac and skeletal muscles from a fast (Katsuwonus pelamis) and a slow (Cyprinus carpio) fish. Can J Zool 70:1246-1253.

Muir B. and G. Hughes. 1969. Gill dimensions for 3 species of tunny. J Exp Biol 51:271-285.

Poupa O., L. Lindstrom, A. Maresca, and B. Tota. 1981. Cardiac growth, myoglobin, proteins and DNA in developing tuna (Thunnus thynnus thynnus L.). Comp Biochem Physiol A 70: 217-222.

Sepulveda C. and K.A. Dickson. 2000. Maximum sustainable speeds and cost of swimming in juvenile kawakawa tuna (Euthynnus affinis) and chub mackerel (Scomber japonicus). J Exp Biol 203:3089-3101.

Sepulveda C.A., K.A. Dickson, and J.B. Graham. 2003. Swimming performance studies on the eastern Pacific bonito Sarda chiliensis, a close relative of the tunas (family Scombridae). I. Energetics. J Exp Biol 206:2739-2748.

Sharp G.D. and S. Pirages. 1978. The distribution of red and white swimming muscles, their biochemistry, and the biochemical phylogeny of selected scombrid fishes. Pp. 41-78 in G.D. Sharp and A.D. Dizon, eds. The Physiological Ecology of Tunas. Academic Press, New York.

Shiels H.A., J.M. Blank, A.P. Farrell, and B.A. Block. 2004. Electrophysiological properties of the L-type $\mathrm{Ca}^{2+}$ current in cardiomyocytes from bluefin tuna and Pacific mackerel. Am J Physiol 286:R659-R668.

Steffensen J.F. 1989. Some errors in respirometry of aquatic breathers: how to avoid and correct for them. Fish Physiol Biochem 6:49-59.

Steffensen J.F., P.G. Bushnell, and H. Schurmann. 1994. Oxygen consumption in four species of teleosts from Greenland: no evidence of metabolic cold adaptation. Polar Biol 14:49-54.

Stevens E.D. and J.M. McLeese. 1984. Why bluefin tuna have warm tummies: temperature effect on trypsin and chymotrypsin. Am J Physiol 246:R487-R494.

Thorarensen H., P.E. Gallaugher, A.K. Kiessling, and A.P. Farrell. 1993. Intestinal blood flow in swimming chinook salmon Oncorhynchus tshawytscha and the effects of haematocrit on blood flow distribution. J Exp Biol 179:115-129.

Tucker V.A. 1970. Energetic cost of locomotion in animals. Comp Biochem Physiol 34:841-846.

Videler J.J. 1993. Fish Swimming. Vol. 10. Fish and Fisheries. Chapman \& Hall, London.

Vornanen M., H. A. Shiels, and A. P. Farrell. 2002. Plasticity of excitation-contraction coupling in fish cardiac myocytes. Comp Biochem Physiol A 132:827-846.

Webb P.W., P.T. Kostecki, and E.D. Stevens. 1984. The effect of size and swimming speed on locomotor kinematics of rainbow trout. J Exp Biol 109:77-95. 